\title{
Self-Regulated Learning in A Massive Open Online Course: A Review of Literature
}

\author{
Hizam Min ${ }^{1 *}$ (), M. Khalid M. Nasir ${ }^{1}$ (1)
}

${ }^{1}$ Faculty of Education, Universiti Kebangsaan Malaysia, Selangor, MALAYSIA

*Corresponding Author: hizammin@gmail.com

Citation: Min, H., \& Nasir, M. K. M. (2020). Self-Regulated Learning in A Massive Open Online Course: A Review of Literature. European Journal of Interactive Multimedia and Education, 1(2), e02007. https://doi.org/10.30935/ejimed/8403

\begin{abstract}
Massive Open Online Course (MOOC) is an online course accessible through the internet to deliver online learning content to anyone who is interested to gain knowledge in the various fields offered. Some of the accessible materials are video clips, downloadable and plenary discussion in social media activity. In addition, there are interactive forums that build a community of educators and students. This paper reviews the ongoing research trends from ongoing research in various disciplines at MOOC. Its background reviews are structured descriptively and chronologically from the information collected. This paper then focuses on the role of Self-Regulated Learning (SRL) as a strong support to MOOC. The advantages of MOOC are very beneficial, it enables more people to gain knowledge at no cost, without space or temporal constraints, in online courses over the web. The findings indicate the SRL has a great impact in the MOOC achievement. Although there are obstacles in providing solutions for the implementation of MOOCs to achieve the best results. Future studies should look at more complex and challenging current situations for the implementation of MOOCs in keeping with the latest modern learning.
\end{abstract}

Keywords: Massive Open Online Course (MOOC), Self-Regulated Learning (SRL), interaction, Learning Management System (LMS)

Received: 1 Jun. $2020 \bullet$ Accepted: 28 Jun. 2020

\section{INTRODUCTION}

A free online learning course that is designed for the participation of big numbers of geographically dispersed trainees is called massive open online course (MOOC). The privilege of MOOC is that there is no entry requirement. Thus, the courses offered are globally recognized. All well-known universities and institutions provide the best courses without the need to complete the entire programs of study as normally implemented. With the help of advanced internet connection and diffusion of IT facilities, a newly formed type of eLearning platform draws worldwide focus, that it makes use of IT resources to help facilitate students and faculty in education.

MOOC, terminology first was invented by Dave Cormier and Bryan Alexander in 2008, stands for massive open online courses (Daniel, 2012). MOOC development targets staff who are interested in enhancing their knowledge and skills in their respective fields without having to attend lectures face-to-face with lecturers as they do in their learning environment in higher education institutions. (McAuley et al., 2010). This type of e-Learning system indicates a considerable amount of difference than the traditional classroom style education because it enables learners to overcome the spatial, temporal and environmental limits.
The MOOC appeared in 2011. It grows every day in terms of courses offered and participants. It starts with a series of educational videos developed by professors from Stanford University and released through an open online platform supported by free web resources. The most upward growth for MOOC is 2012 because there were many other online course sites have sprung up such as COURSERA in April, 2012 and EDX (collaboration of MIT University and Harvard University) in May 2012 (Castillo et al., 2015). From there it can be seen that knowledge can be shared with everyone around the world and is excited by the interaction and virtual connections that can be made through active online discussions. So to leverage the internet by connecting (connective) every person who wants to learn, to share knowledge widely and to see how far it can go. The MOOC can also provide opportunities for anyone around the world, who wants to gain education but is not able to get the same quality of the education, no matter who and where you are.

Learning via MOOC platforms requires excellent self -disciplined management to succeed because the learner has full autonomy to control and manage the learning. Therefore, SRL is the most prominent principle to guarantee one's success in MOOC. SRL in a MOOC boosts the students to plan and regulate their own learning, it guides to gain better insights into how they learn and what works best for them. Consequently, the individual is responsible for his learning objectives and performs at a higher-level of academic performance. It is 
undeniable that SRL plays important contributions in MOOC learning. Indeed, SRL skills and strategies have strongly supported the student's learning success. However, it is students' choice to determine and practice the most applicable strategy to their learning process (Wong et al., 2018). On that account, this review is conducted to impart a list of effective SRL in MOOC conducted by researchers in their research papers.

\section{LITERATURE OVERVIEW}

Self-regulated Learning (SRL) is the ability to understand and control one's learning environment. It includes goal setting, selfmonitoring, self-instruction, and self-reinforcement (Schraw et al., 2006). Basically, it refers to learning that is guided by metacognition, strategic action and motivation to learn. Instead, SRL is a self-directive process and set of behaviours whereby learners transform their mental abilities into skills (Zimmerman, 2002) and habits through a developmental process (Butler, 2002) that results from guided practice and feedback (Paris \& Paris, 2001).

The SRL plays important role in making MOOC learning successful, this invites the researchers to start exploring the effectiveness of SRL interventions in this context. Kizilcec, PerezSanagustín, et al. (2016) conducted a study on 17 successful learners of a MOOC to write down study tips for those starting the MOOC. As an intervention, the tips were presented to half of the learners in a precourse survey. These learners were asked to rate the usefulness of the tips. The learners in the control group were not presented the tips; they were presented the course topics and were asked to rate the usefulness of these topics for their career. To determine the effectiveness of the intervention, students' persistence and achievement were measured. No differences were found between those learners who had and had not been presented the study tips in the survey. The author gave some explanation of the shortcomings significant differences, including that the intervention may be too small and insufficient for others course.

Yeomans and Reich (2017) also applied interventions in pre-course reviews. They measure the effect of intervention upon completion of the course, in accordance with Kizilcec et al. (2016), as well as on course verification. As planning the targetted students are asked to explain the specific plans they have to study the course content and complete the quiz and task. Implementation of the plan led to an increase in verification and verification rates. The results show that SRL intervention in MOOC can be effective; achievements are enhanced by linking the intervention with course content and motivation students to participate in SRL. In addition, maintaining teaching presence (Baharudin et al., 2018; Nasir, Surat, et al., 2018) and social presence (Nasir, Mansor, et al., 2018) could also support students to engage in SRL effectively.

According to Cho and Shen (2013), SRL has been identified as one of the key factors for students' success in the traditional online learning environment. The results of a survey study examining the empirical literature published from 1994 to 2006 show that self-efficacy is positively related to the use of learning strategies, satisfaction with online courses, the possibility of enrolling in online courses, and academic performance supported by Artino (2007). Time management, metacognition, business rules, and critical thinking have a significant positive relationship with academic achievement in MOOCs. Abbakumov et al. (2018) study the implementation of the assessment conducted using data from MOOC provider sources. Evaluation data were reviewed using Classical Test Theory (CTT) and Item Response Theory (IRT) models to see if they were relevant. The findings can improve the evaluation or assessment of MOOCs as they are always up to date and in line with students' learning.

There are various aspects of MOOC that can be studied such as:1) student participation and academic performance; 2) MOOC design and curriculum; 3) self-learning and social learning; 4) social network analysis and online learning; and 5) academic motivation, attitude and success. The following research questions are drawn from the literature on SRL in the MOOC. The extent to which SRL impacts on MOOC learning has been identified. Next look at the SRL strategies identified in the study on SRL in MOOC.

\section{RESEARCH MATERIALS AND METHODS}

This research was conducted based on the procedures of systematic reviews in social science. Systematic reviews are defined as literature reviews that stick closely to a set of scientific methods that explicitly aim to limit systematic error (bias), mainly by attempting to identify, appraise and synthesize all relevant studies (of whatever design) in order to answer a particular question (or set of questions (Petticrew \& Roberts, 2008). For this study, the research questions are uprooted from the literature on SRL in the online learning environment regarding the status of studies on SRL in MOOC published from 2015 to 2020. What are the effects and contributions of SRL learning as well as SRL strategies identified in studies on SRL in the MOOC? Next, what are the criteria established to decide the types of studies? Papers were limited to studies written in English and issued in peer-reviewed journals in order to focus on quality, practicality and accessibility. In addition, inclusion and exclusion criteria were clearly defined to present the results of the search and select the most relevant studies.

Papers on SRL in MOOCs were searched through a University's library website (UKM) and the Google Scholar website. The search query resulted in more than 600 hits in Education Source such as Science Direct, Elsevier, ResearchGate, Journal of e-Skills and Life Long Learning, Scientific Research Publishing, and International Review of Research in Open and Distributed Learning. It's also resulted in 100 hits in Science Direct. In addition, there were 600 hits in Google Scholar according to relevance. With respect to search terms, a total of 31 search terms were used in the first selection step. Titles, keywords, and abstracts of searched articles were read and the inclusion criteria were applied to screen the inappropriate articles. Through this process, many articles were eliminated, and a total of 50 articles remained. In the second selection step, titles and abstracts as well as contents of the 30 articles were read. Using the inclusion and exclusion criteria, 8 articles were excluded from the Education Source and additional 19 articles were also excluded: and 6 articles from Web of Science. Finally, a total of 10 articles was selected as the most appropriate studies in this systematic review.

\section{FINDINGS}

SRL contains various skills and strategies incorporate planning, organizing, self-observing and self- assessing which lead to an active learning among students. Zimmerman (2013) identified the 


\begin{tabular}{lcr|}
$\begin{array}{l}\text { Task interest/value } \\
\text { Causal attribution }\end{array}$ & Help-seeking & Task strategies \\
Self-efficacy & Self-evaluation & Time management \\
Imagery & SRL & Self-instruction \\
Self-recording & Adaptive/defensive \\
Self-satisfaction/affect & Metacognitive monitoring \\
Goal orientation & \multicolumn{2}{c}{ Outcome expectation } \\
\multicolumn{2}{c}{ Environmental structuring } \\
\end{tabular}

Figure 1. SRL Strategy

Table 1. Frequency of SRL Strategy

\begin{tabular}{ccc}
\hline Subprocess/strategy & Frequency & (\%) \\
\hline Task interest/value & 175 & 37.72 \\
\hline Causal attribution & 68 & 14.66 \\
\hline Time management & 59 & 12.72 \\
\hline Self-efficacy & 53 & 11.42 \\
\hline Goal orientation & 27 & 5.82 \\
\hline Goal setting & 20 & 4.31 \\
\hline Help-seeking & 18 & 3.88 \\
\hline Outcome expectation & 14 & 3.02 \\
\hline Self-instruction & 12 & 2.59 \\
\hline Self-satisfaction/affect & 9 & 1.94 \\
\hline Environmental structuring & 3 & 0.65 \\
\hline Task strategies & 3 & 0.65 \\
\hline Self-evaluation & 2 & 0.43 \\
\hline Attention focusing & 1 & 0.22 \\
\hline Adaptive/defensive & 0 & 0.00 \\
\hline Imagery & 0 & 0.00 \\
\hline Metacognitive monitoring & 0 & 0.00 \\
\hline Self-recording & 0 & 0.00 \\
\hline
\end{tabular}

involvement of 18 SRL strategies as shown in Figure 1. Glaringly, it can be seen that task interest/value strategy had the highest figures (37.72\%) to prompt the students in accomplishing their MOOC (Table 1) as being inferred in a research conducted by Erwin et al. (2019).

Furthermore, one of the SRL strategies was conducted at the early stage of a course. According to Davis et al. (2016), comparison between two groups of students, the first was given a research module planning as well as actively disclosed among them. Unlike, the second group was not been provided with any materials and no interaction occurred. The result showed that providing aids and guides gear to absolute positive outcomes. Besides, video aids related to the courses do play important guide for students, they would be more proactive and dynamic in their learning.

Zimmerman dan Pintrich are mainly two recognized models in SRL. The focal point of Zimmerman model is on three Stages of Learning: forethought stage, performance stage and self- reflection stage. Contrarily, Pintrich Model interprets Metacognitive strategies, Cognitive strategies and Resource management. However, the learning strategies vary depending on the learning contents, curriculum as well as pedagogy. Findings revealed that self- efficacy, individual's background and SRL tips grant great influence of SRL in MOOC. Nevertheless, individual's planning and objectives are both intrinsic motivations to enhance their learning effectively.

Based on the research conducted by Lee et al. (2019) investigated strategy in SRL in MOOC, SRL strategy comprises of Cognitive and Metacognitive Regulation strategies which relate to rehearsal, elaboration and organisation meanwhile Behavioural and Contextual Regulation strategies explain help seeking, time management and effort regulation. Lastly, Motivational Regulation strategies focus more on self-efficacy and task value. Unquestionably, time management is the most prominent aspect that impacts MOOC learning and that consequently, quite a few students could not manage to end MOOC.

Park, Cha, and Lee (2016) developed a design guide for learning analytics to promote student SRL in MOOCs, as shown in Table 2. The design was a helpful guideline for any organizer in conducting effective MOOC to ensure the students would be able to score excellent achievements without any difficulties.

Self-motivation beliefs influence these goals and plans. After the forethought phase, learners proceed to the performance phase where they carry out their plans by exercising self-control and selfobservation. To effectively learn, learners manage their time, structure their environment, and apply useful learning strategies. In addition, they monitor their learning progress. The self-reflection phase comes after the performance phase. Learners evaluate their learning progress based on the information derived from metacognitive monitoring in the performance phase and the feedback they are given. Learners reflect on their goals, plans and strategies, and make use of these information to form new goals and plans.

Table 2. Design of learning analysis guidelines for promoting SRL in MOOC

\begin{tabular}{|c|c|}
\hline Dimension of strategy SRL & Guidelines for the final design to facilitate SRL in the MOOC environment \\
\hline \multirow[t]{2}{*}{ Self-evaluation } & Content analysis of learner reflection \\
\hline & Learning history compared to others (achievements, progress, activities, e-portfolio, etc.) \\
\hline \multirow[t]{2}{*}{ Organising and transforming } & Learners' preferred contents types (video clips, texts, images, voices, etc.) \\
\hline & Student's participant activity records to upload and author contents \\
\hline \multirow[t]{2}{*}{ Goal setting and planning } & Setting learning objectives and plans for effective time management \\
\hline & Monitoring learners' plans \\
\hline Rehearing and memorising & Details about participation in the exercise, discussion, homework, etc. \\
\hline Reviewing records & Quantitative and qualitative analysis of learning exercise such as quiz, discussions and exams for reviewing \\
\hline Seeking information & References and links referred by learners and others \\
\hline Seeking social assistance & Q\&A to overcome problems or solve the problems \\
\hline \multirow[t]{2}{*}{ Self-consequences } & History of certificates or credits with invested time and earned achievement scores \\
\hline & Enrolled and completed rates of courses monthly or annually \\
\hline Structuring personalised learning environments & Recommending courses for each learners' level or interest \\
\hline
\end{tabular}


Table 3. Template design of MOOC focusing on self-regulation and self-motivation

\begin{tabular}{lll}
\hline Type of activity & Activity detail & OER support activities \\
\hline $\begin{array}{l}\text { Recognize low self-regulated or } \\
\text { self-motivated students }\end{array}$ & Describe and justify the procedure to identify such students. \\
\hline Self-regulation promotion & $\begin{array}{l}\text { Generalized or voluntary call to identify low self-regulated students to perform } \\
\text { activities such as reducing distractions, improving organization, distinguishing } \\
\text { important information, looking for assistance, etc. Offer at least seven activities. }\end{array}$ \\
\hline
\end{tabular}

Espinosa, Tenorio, and Ramírez-Montoya (2015) proposed a template design for MOOCs focusing on self-motivation and selfregulation to increase persistence and active participation of less motivated-students in a MOOC. Table 3 shows examples of a MOOC design template focusing on SRL.

According to Lambert (2020) who investigates the development of MOOCs through reviews and findings of MOOC-related journals published from 2014 to 2018 in the same area of acceptance for each student as well as the needs or aspirations of the community. MOOC strives to change society's perspective with the exposure of knowledge through MOOC It aims to help the country for the future of a better country. The study from Marta-Lazo et al. (2018) also agrees with the importance of care and This study concludes that MOOCs aimed at expanding participation in education are global practices in line with more MOOCs and aim to bridge the gap in various aspects of the economy.

\section{DISCUSSION}

There are many things that attract students' interest in the MOOC such as low cost to obtain certificates as well as extensive learning autonomy. Course activities are organized in a timely manner for students. During the week of the regular course, of course the activities consist of a series of video lectures to deliver course content followed by a discussion guide to stimulate thinking key concepts, and assessments to assess the knowledge gained from video lectures. Students are not bound by sequences the course activities that have been planned, because they have the autonomy to continue their own sequence of learning activities, such as when to watch a video lecture, and which course activities they should follow after watching a video lecture. Moreover, students are free to skip any course activities.

Bralić and Divjak (2018) who studies the use of blended learning in the implementation of MOOC. Studies on the use of MOOCs in the classroom (Blended learning). The finding of this study can benefit educators and also detect barriers or barriers to implementation such as the technology aspect. Domingo et al. (2019) further investigated the implications of MOOCs on the professional practice of participants involved in MOCC. They are qualitatively and qualitatively mixed. Interviews were also conducted to obtain information directly from the sample. The findings obtained include participants participating in MOOCs for their work purposes and knowledgeable participants will be more likely to take advantage of the MOOC they are pursuing.

Therefore, learning at MOOC requires students to monitor their own learning and engage with course activities in a way that will optimize their learning. This shows that learning in MOOC requires students to be self-regulated to their learning. Self-directed learning (SRL) is a broad framework that includes motivation, metacognitive, cognitive, affective, and behavioral aspects of learning (Panadero, 2017). Several SRL models have been developed for stage and process concepts SRL. According to the study of Puustinen and Pulkkinen (2001), the SRL model is usually described by processes that operate in the phase of the cycle. For example, in Zimmerman's SRL model, the learning process works in three cycles phase: initial thinking, achievement, and self-reflection (Zimmerman \& Moylan, 2009).

Success in MOOC with SRL support depends on the models being used such as Zimmerman models that focus on early stages of thinking (e.g., goal setting and planning), performance phases (e.g., learning and task strategies) and phases of self-reflection (e.g., self-evaluation) (Lan \& Jiutong, 2018). This helps achieve the goals and goals of following the MOOC with the support of SRL to successfully complete the course.

According to Jansen et al. (2020), descriptions of videos related to content requirements and descriptions related to courses being followed are more helpful than providing guidance / tips. Instead embedding technological aids that adaptively support SRL throughout the course could be better support learners in MOOCs. The goals of following the MOOC also contribute to the success of the MOOC despite being assisted by the SRL. There are some who join the MOOC just for fun (no goals) compared to those who follow for the job or add knowledge for the future. SRL support only helps this group ends their MOOC well and effectively.

\section{CONCLUSION}

This systematic review has catered an overview of current SRL studies in MOOC context. The synthesis revealed us that Zimmerman's and Pintrich's SRL model were mainly used in current SRL studies in MOOC context. Findings indicated self-efficacy, participants' background (e.g. field professionals and program types) and SRL prompts can affect the use of SRL in MOOCs. Goal setting and planning were highly supported SRL processes to improve learning performance. Furthermore, self-motivation and goal setting are significant in the MOOC platform because they help students with selfregulated learning. Self-regulated students are more likely to stay and complete the course. It proves that students possess SRL strategies; however, these strategies are not related to their learning retention in MOOC. Basically, students with higher SRL levels accomplish better academic performance than those with lower SRL, face-to-face and online learning environments.

\section{REFERENCES}

Abbakumov, D., Desmet. P., \& Noortgate, W. V. (2018). Measuring student's proficiency in MOOCs: multiple attempts extensions for the Rasch model. Heliyon, 4, 1-15. https://doi.org/10.1016/ j.heliyon.2018.e01003 
Artino, A. R. (2007). Online Military Training: Using a Social Cognitive View of Motivation and Self-Regulation to Understand Students' Satisfaction, Perceived Learning, and Choice. Quarterly Review of Distance Education; Charlotte, 8(3), 191-202. Retrieved from https://search.proquest.com/openview/19eac88d3ba42f513f1b0f0 e90da4b17/1?pq-origsite $=$ gscholar\&cbl=29705

Baharudin, H., Nasir, M. K. M., Yusoff, N. M. R. N., \& Surat, S. (2018). Assessing Students' Course Satisfaction with Online Arabic Language Hybrid Course. Advanced Science Letters, 24, 350-352. https://doi.org/10.1166/asl.2018.12005

Bralić, A., \& Divjak, B. (2018). Integrating MOOCs in traditionally taught courses: achieving learning outcomes with blended learning. International journal of educational technology in higher education, 15(2), 1-16. https://doi.org/10.1186/s41239-017-0085-7

Butler, D. L. (2002) Qualitative Approaches to Investigating SelfRegulated Learning: Contributions and Challenges. Educational Psychologist, 37(1), 59-63. https://doi.org/10.1207/S15326985EP3 701_7

Castillo, N. M., Lee, J., Zahra, F. T., \& Wagner, D. A. (2015). MOOCs for Development: Trends, Challenges, and Opportunities. Journal Articles (Literacy.org), 11(2). 35-42. Retrieved from https://repository.upenn.edu/literacyorg_articles/6

Cho, M., \& Shen, D. (2013). Self-regulation in online learning. Journal Distance Education, 34(3). 290-301. https://doi.org/10.1080/ 01587919.2013 .835770

Daniel, J. (2012). Making Sense of MOOCs: Musings in a Maze of Myth, Paradox and Possibility. Journal of Interactive Media for Education, 2012(3), p.Art.18. https://doi.org/10.5334/2012-18

Davis, D., Chen, G., Van, T., Zee, T. V. D., Hauff, C., \& Houben, G. J. (2016). Retrieval practice and study planning in MOOCs: Exploring classroom-based self-regulated learning strategies at scale. European Conference on Technology Enhanced Learning. 57-71. https://doi.org/10.1007/978-3-319-45153-4_5

Domingo, M., Paran, A., Révész, A., \& Palange, A. (2019). Exploring factors that influence the impact of MOOC learning on participants' professional practice. Institute of Education, University College London. Retreived from https://london.ac.uk/sites/default/files/ leaflets/ExploringFactorsThatInfluenceTheImpactOfMOOCs_Fin al.pdf

Erwin, H., Susie, L. G., Sara, G. M., Curtis, J. B., \& Bernard, R. R. (2019) Goal Setting and MOOC Completion: A Study on the Role of Self-Regulated Learning in Student Performance in Massive Open Online Courses. International Review of Research in Open and Distributed Learning, 20(3). https://doi.org/10.19173/irrodl.v20i4. 4270

Espinosa, B. J. G., Tenorio, G. C., \& Ramírez-Montoya, M. (2015). Selfmotivation challenges for student involvement in the Open Educational Movement with MOOC. RUSC. Universities and Knowledge Society Journal, 12(1), 91-103. https://doi.org/10.7238/ rusc.v12i1.2185

García, B. J., Tenorio, G. C., \& Ramírez, M. S. (2015). Self-motivation challenges for student involvement in the Open Educational Movement with MOOC. RUSC. Universities and Knowledge Society Journal, 12(1), 91-103. https://doi.org/10.7238/rusc.v12i1.2185
Jansen, R. S., Leeuwen, A. V., Janssen, J., Conijn, R., \& Kester, L. (2020). Supporting learners' self-regulated learning in Massive Open Online Courses. Computers \& Education, 146, 103771. https://doi.org/10.1016/j.compedu.2019.103771

Kizilcec, R. F, Perez-Sanagustín, M., \& Maldonado, J. J. (2016). Recommending Self-Regulated Learning Strategies Does Not Improve Performance in a MOOC. L@S 16: Proceedings of the Third (2016) ACM Conference on Learning @ Scale, 101-104. https://doi.org/10.1145/2876034.2893378

Lambert, S. R. (2020). Do MOOCs contribute to student equity and social inclusion? A systematic review 2014-18. Computers \& Education, 145, 103693. https://doi.org/10.1016/j.compedu.2019. 103693

Lan, M., \& Jiutong, L. (2018). Understanding Self-Regulated Learning Studies in MOOCs: A Systematic Review. Paper presented at the AERA 2018 Annual Metting, New York.

Lee, D., Watson, S. L., \& Watson, W. R. (2019). Systematic literature review on self-regulated learning in massive open online courses. Australasian Journal of Educational Technology, 35(1). 28-41. https://doi.org/10.14742/ajet.3749

Marta-Lazo, C., Osuna-Acedo, S., \& Gil-Quintana, J. (2018). sMOOC: A pedagogical model for social inclusion. Heliyon, 5, 2405-8440. https://doi.org/10.1016/j.heliyon.2019.e01326

McAuley, A., Stewart, B., Siemens, G., \& Cormier, D. (2010). The MOOC Model for Digital Practice. The University of Prince Edward Island. CC Attribution

Panadero, E. (2017). A Review of Self-regulated Learning: Six Models and Four Directions for Research. Frontiers in Psychology, 8, 422. https://doi.org/10.3389/fpsyg.2017.00422

Paris, S. G., \& Paris, A. H. (2001). Classroom applications of research on self-regulated learning. Educational Psychologist, 36(2), 89-101. https://doi.org/10.1207/S15326985EP3602_4

Park, T. J., Cha, H. J., \& Lee, G. Y. (2016). A study on design guidelines of learning analytics to facilitate self-regulated learning in MOOCs. Educational Technology International, 17(1), 117-150. Retrieved from http://kset.or.kr/eti_ojs/index.php/instruction/ article/view/61

Petticrew, M., \& Roberts, H. (2006). Systematic Reviews in the Social Sciences: A Practical Guide. Oxford. Counselling and Psychotherapy Research, 6(4), 304-305. https://doi.org.10.1080/1473314060098 6250

Puustinen, M., \& Pulkkinen, L. (2001). Models of Self-regulated Learning: A review. Scandinavian Journal of Educational Research 45(3), 269-286. https://doi.org/10.1080/00313830120074206

Schraw, G., Crippen K. J., \& Hartley K., (2006). Promoting SelfRegulation in Science Education: Metacognition as Part of a Broader Perspective on Learning. Research in Science Education, 36, 111-139. https://doi.org/10.1007/s11165-005-3917-8

Wong, J., Baars, M., Davis, D., Zee, T. V. D., Houben, G., \& Paas, F. (2019). Supporting Self-Regulated Learning in Online Learning Environments and MOOCs: A Systematic Review. International Journal of Human-Computer Interaction, 35(4-5), 356-373, https://doi.org/10.1080/10447318.2018.1543084 
Yeomans, M., \& Reich, J. (2017). Planning prompts increase and forecast course completion in massive open online courses. Proceedings of the Seventh International Learning Analytics \& Knowledge Conference. Vancouver British Columbia Canada. 464-473. https://doi.org/10.1145/3027385.3027416

Zimmerman, B. J. (2002). Becoming a Self-Regulated Learner: An Overview. Journal Theory into Practice, 41(2). 64-70. https://doi.org/10.1207/s15430421tip4102_2
Zimmerman, B. J. (2013). From cognitive modeling to self-regulation: A social cognitive career path. Educational Psychologist, 48(3), 135147. https://doi.org/10.1080/00461520.2013.794676

Zimmerman, B. J., \& Moylan, A. R. (2009). Self-regulation: Where metacognition and motivation intersect. In D. J. Hacker, J. Dunlosky \& A. C. Graesser (Eds.), Handbook of Metacognition in Education. New York: Routledge. Retrieved from https://psycnet.apa.org/record/2010-06038-016 